\title{
The Intervention Plan of Water Resource
}

\author{
Wei Li \\ School of Wei Li,North China Electric Power University,Baoding 071000,China \\ 664006843@qq.com,
}

Keywords: L-WCSI, waterresource, in the future

\begin{abstract}
First, I establish the L-WSCI model to compare water resource. There are 5 differentfeasible and efficient intervention plans: Water Project-—-south-to-north water diversion, desalination of sea water, recycled water treatment technologies,technology of drop Irrigation and urban greenbelt. We take all of 5 plans into consideration. Even so, which maximizes the water supply, the situation of water scarcity could only relieve tension and stress but could not solve this problem thoroughly. These results imply that the chosen region is an absolute scarcity area. Finally, we use the data in Task 2 forecast the water resource situation in next 15 years. The results show that there is little possibility that water would become a critical issue in the future.
\end{abstract}

\section{Introduction}

I choose one of the absolute scarcity region_-Tianjing as the study region.Tianjin is a metropolis in coastal northeastern China and one of the five national central cities of China, with a total municipal population of $15,200,000$. It is governed as one of the four direct-controlled municipalities of the PRC and is thus under direct administration of the central government. Tianjin borders Hebei Province and Beijing Municipality, bounded to the east by the Bohai Gulf portion of the Yellow Sea. Part of the Bohai Economic Rim, it is the largest coastal city in northern China. In terms of urban population, Tianjin is the fourth largest in China, after Shanghai, Beijing, and Guangzhou. In terms of administrative area population, Tianjin ranks fifth in Mainland China. But compared to other regions, Tianjing is a thirsty place.

\section{The L-WSCI Model}

The L-Wsci Model could be described byequation.

$$
W_{s c i}=\left(\frac{4000 * \alpha}{\left(\frac{100}{100-p}\right) \beta e^{\lambda t}(\varepsilon+\gamma+\delta)\left(\frac{100}{100-\kappa}\right)+h+b}\right)
$$

Then we use the data to check the Model, The results are shown in Table1.

Table1:Modified Data

\begin{tabular}{cccccc}
\hline Hainan & Anhui & Hunan & Yunnan & Kweichow & Honan \\
0.53 & 4.84 & 4.93 & 7.27 & 18.30 & 27.52 \\
Shangtung & Kansu & Chungking & $\begin{array}{c}\text { Inner } \\
\text { Mongolia }\end{array}$ & Tianjing & \\
30.64 & 42.14 & 66.40 & 146.90 & 360.34 & \\
\hline
\end{tabular}

In order to make the result more obvious based on the value of the L-Wsci Model and the real water resource situation we found on the website of the ministry of water resources of the Peoples Republic of China. The water conditions in an area can be categorized as: no stress, stress, scarcity, and absolute scarcity (Table2). 
Table2:Classification

\begin{tabular}{cc}
\hline L - Wsci & Condition \\
\hline$<\mathbf{1 0}$ & No Stress \\
$\mathbf{1 0 - 2 0}$ & Stress \\
$\mathbf{2 0 - 4 0}$ & Scarcity \\
\hline $\mathbf{4 0}$ & Absolute Scarcity \\
\hline
\end{tabular}

From the Table2, we can find that in most areas, namely, Inner Mongolia, Tianjing andKansu, (Figure 1)the model fits well to the real data of UN water scarcity map.

\section{The Intervention Plan}

The Analysis of Intervention Plan.In The L-Wsci Model, some of the parameters could change due to infrastructures, (for example, desalinization plants, water harvesting techniques or undiscovered aquifers),for example $b, k, p, h, \beta, \lambda$, while others could not, for example $\alpha, \varepsilon, \gamma, \delta$.In order to make a better environment in the study region in future, we try our best to make the optimum solution in the changeable parameters by intervention plan.

Details about the Projects.There are 5 different feasible and efficient techniques : Water Project_—south-to-north water diversion, desalination of sea water, recycled water treatment technologies, technology of drop Irrigation and urban greenbelt.

According to the data from Water Affairs Bureau of Tianjing, these methods could be used in the near future and the quantized effects of these projects could be found the technical papers which are shown in the following table(table 3).

Table 3: Effect of different intervention plans

\begin{tabular}{|cc|}
\hline Intervention Plan & Effect \\
\hline south-to-north water diversion & +7.6 \\
\hline desalination of sea water & +0.175 \\
\hline recycled water treatment technologies & +1.5 \\
\hline technology of drop Irrigation & $-10 \%$ \\
\hline urban greenbelt & --- \\
\hline
\end{tabular}

We plunge these parameters of 2012 into theequation, then we obtain the different index of The L-Wsci Model and following table shows the results(table 4).

Table 4: the Results with intervention plans

\begin{tabular}{ccc}
\hline Before optimization & After optimization & Change Rate \\
\hline 265.8324 & 245.5478 & $-7.63 \%$ \\
\hline
\end{tabular}

From the Table 4, we can find that even if the study object implements the ideal intervention plan, which maximizes the water supply, the situation of water scarcity could only relieve tension and stress but could not solve this problem thoroughly. The urban greenbelt does not affect the quantity of clean water directly. It effects the water circulation. It would be easier that atmospheric rainfall turn into ground water when there is more urban greenbelt in a region, especially for the area like Tianjing.

We assume that there is a soar in urban greenbelt. Then we calculate the results and that is shown below (table 5).

Table 5:AssumptionSimulation

\begin{tabular}{cccccc}
\hline $\boldsymbol{\gamma}=\mathbf{3 0 m}^{\mathbf{2}}$ & $\begin{array}{c}\text { Change } \\
\text { Rate }\end{array}$ & $\boldsymbol{\gamma}=\mathbf{5 0 m}^{\mathbf{2}}$ & $\begin{array}{c}\text { Change } \\
\text { Rate }\end{array}$ & $\boldsymbol{\gamma}=\mathbf{7 7 . 7 \mathbf { m } ^ { \mathbf { 2 } }}$ & $\begin{array}{c}\text { Change } \\
\text { Rate }\end{array}$ \\
\hline 222.7102 & $16.22 \%$ & 202.3631 & $23.88 \%$ & 180.1445 & $32.23 \%$ \\
\hline
\end{tabular}

We could find that it is an efficient way to mitigate water scarcity by improving the area of urban greenbelt. But it cannot the situation that the region is acute shortage of water. Besides, there is no 
evident or papers that prove the intervention plan have a negative impact on the surrounding areas or the entire water ecosystem.

\section{The Future}

I assume that effects of the intervention plans mentioned before is constant during our study time. I add these new water resources to the results. And according to these data, we calculate the final result and the following table shows that (table 6).

Table 6:Final Results

\begin{tabular}{lccc}
\hline Year & Before optimization & After optimization & change rate \\
\hline $\mathbf{2 0 1 6}$ & 265.1381017 & 255.9770343 & $-3.46 \%$ \\
\hline $\mathbf{2 0 1 7}$ & 273.2052693 & 263.4070261 & $-3.59 \%$ \\
\hline $\mathbf{2 0 1 8}$ & 280.4845849 & 270.3443767 & $-3.62 \%$ \\
\hline $\mathbf{2 0 1 9}$ & 287.4083346 & 277.0732598 & $-3.60 \%$ \\
\hline $\mathbf{2 0 2 0}$ & 296.7816982 & 285.4985592 & $-3.80 \%$ \\
\hline $\mathbf{2 0 2 1}$ & 308.2645285 & 295.4010341 & $-4.17 \%$ \\
\hline $\mathbf{2 0 2 2}$ & 320.2620024 & 305.7004982 & $-4.55 \%$ \\
\hline $\mathbf{2 0 2 3}$ & 332.004405 & 315.8801674 & $-4.86 \%$ \\
\hline $\mathbf{2 0 2 4}$ & 314.3587476 & 297.9423621 & $-5.22 \%$ \\
\hline $\mathbf{2 0 2 5}$ & 320.4671663 & 302.5952877 & $-5.58 \%$ \\
\hline $\mathbf{2 0 2 6}$ & 327.535705 & 307.8999894 & $-5.99 \%$ \\
\hline $\mathbf{2 0 2 7}$ & 333.0701495 & 312.1925797 & $-6.27 \%$ \\
\hline $\mathbf{2 0 2 8}$ & 339.414889 & 317.0412956 & $-6.59 \%$ \\
\hline $\mathbf{2 0 2 9}$ & 332.7683435 & 313.053324 & $-5.92 \%$ \\
\hline $\mathbf{2 0 3 0}$ & 339.2988182 & 318.0426104 & $-6.26 \%$ \\
\hline
\end{tabular}

According to the results, as the similar results in Task 4, the chosen region nearly could not become less susceptible to water scarcity in the future. But it is worth to implement the intervention plan for reliving the water stress. In the meantime, It is important to note that the through solutions deserve attention. As time goes by, the situation gets worse, we cannot predict it very accurate and we believe the key reason lies in the lack of data. In other words, we only get the data from 2000 to 2012. So the thirteen-year data is too less to forecast the thirteen-year trends of future and the exact results is based on the fact that we have get the data of past forty or fifty years.

Then we take $\gamma$ into considerations and following table shows the results (table 7).

Table 7: Final Result with Impact of $\gamma$

\begin{tabular}{cccccc}
\hline $\boldsymbol{\gamma}=\mathbf{3 0 m} \mathrm{m}^{2}$ & $\begin{array}{l}\text { Change } \\
\text { rate }\end{array}$ & $\boldsymbol{\gamma}=\mathbf{5 0 \mathrm { m } ^ { 2 }}$ & $\begin{array}{l}\text { Change } \\
\text { rate }\end{array}$ & $\boldsymbol{\gamma}=\mathbf{7 7 . 7 m ^ { 2 }}$ & $\begin{array}{l}\text { Change } \\
\text { rate }\end{array}$ \\
\hline $\mathbf{3 0 8 . 9 0 7}$ & $-15.70 \%$ & 280.5292 & $-23.44 \%$ & 248.8652 & $-32.08 \%$ \\
\hline $\mathbf{3 2 9 . 8 4 4 4}$ & $-12.66 \%$ & 299.9228 & $-20.59 \%$ & 266.4466 & $-29.45 \%$ \\
\hline $\mathbf{3 5 4 . 8 5 8 3}$ & $-12.09 \%$ & 321.2266 & $-20.42 \%$ & 283.9538 & $-29.65 \%$ \\
\hline $\mathbf{2 3 1 . 9 8 3 9}$ & $-12.50 \%$ & 209.7671 & $-20.88 \%$ & 185.2021 & $-30.15 \%$ \\
\hline $\mathbf{2 4 1 . 1 7 9 5}$ & $-11.72 \%$ & 218.0362 & $-20.19 \%$ & 192.458 & $-29.56 \%$ \\
\hline $\mathbf{2 5 0 . 6 4 6 7}$ & $-10.64 \%$ & 226.5493 & $-19.23 \%$ & 199.9278 & $-28.72 \%$ \\
\hline $\mathbf{2 6 0 . 3 8 8 6}$ & $-9.40 \%$ & 235.3094 & $-18.13 \%$ & 207.6145 & $-27.76 \%$ \\
\hline $\mathbf{2 7 0 . 4 0 8}$ & $-8.89 \%$ & 244.3193 & $-17.68 \%$ & 215.5206 & $-27.38 \%$ \\
\hline $\mathbf{2 8 0 . 7 0 7 3}$ & $-8.94 \%$ & 253.5814 & $-17.74 \%$ & 223.6486 & $-27.45 \%$ \\
\hline
\end{tabular}




\begin{tabular}{cccccc}
\hline $\mathbf{2 9 1 . 2 8 8 1}$ & $-9.05 \%$ & 263.0976 & $-17.85 \%$ & 232.0005 & $-27.56 \%$ \\
\hline $\mathbf{3 0 2 . 1 5 1 5}$ & $-8.99 \%$ & 272.8692 & $-17.81 \%$ & 240.5778 & $-27.54 \%$ \\
\hline $\mathbf{2 8 6 . 2 3 1}$ & $-8.95 \%$ & 258.403 & $-17.80 \%$ & 227.7376 & $-27.55 \%$ \\
\hline $\mathbf{2 9 1 . 4 9 5 1}$ & $-9.04 \%$ & 263.1079 & $-17.90 \%$ & 231.838 & $-27.66 \%$ \\
\hline $\mathbf{2 9 7 . 5 5 8}$ & $-9.15 \%$ & 268.4692 & $-18.03 \%$ & 236.4543 & $-27.81 \%$ \\
\hline $\mathbf{3 0 3 . 0 4 1 7}$ & $-9.02 \%$ & 273.3648 & $-17.93 \%$ & 240.7157 & $-27.73 \%$ \\
\hline $\mathbf{3 0 8 . 5 9 3 1}$ & $-9.08 \%$ & 278.3217 & $-18.00 \%$ & 245.0315 & $-27.81 \%$ \\
\hline $\mathbf{3 0 6 . 0 6 7 2}$ & $-8.02 \%$ & 276.0198 & $-17.05 \%$ & 242.9819 & $-26.98 \%$ \\
\hline $\mathbf{3 1 1 . 6 2 6 5}$ & $-8.16 \%$ & 280.9857 & $-17.19 \%$ & 247.3072 & $-27.11 \%$ \\
\hline
\end{tabular}

\section{Summary}

According to the results, as the similar results above, the situation in Tianjing greatly improved due to the increase area of urban greenbelt. But it still belongs to the Absolute Scarcity Region.

In conclusion, it is intervention plan that improve the water scarcity in Tianjing, but all of the techniques could not change the status of absolute scarcity.

\section{References}

[1]Amber Brown;Marty D.Matlock,A Review of Water Scarcity Indices and Methodologies.White Paper \#106 | April 2011

[2] Xie N, Liu S. Discrete GM $(1,1)$ and Mechanism of Grey Forecasting Model [J][J]. Systems Engineering-theory \& Practice, 2005, 1: 014.

[3] Brown A, Matlock M D. A review of water scarcity indices and methodologies[J]. White paper, 2011, 106.

[4] China Statistical Yearbookhttp://www.stats.gov.cn/tjsj/ndsj/

[5] Integrated Query Service Platformhttp://www.mwr.gov.cn/zxfw/zhcxfwpt/dfsl/

[6] Tianjing Maphttps://en.wikipedia.org/wiki/Tianjin

[7]de Fraiture C. Assessment of potential of food supply anddemand using the Watersim model[J]. Columbo: International Water Management Institute, 2005.

[8]Gober P, Wentz E A, Lant T, et al. WaterSim: a simulation model for urban water planning in Ph oenix, Arizona,USA[J].Environment and Planning B: Planning and Design, 2011, 38(2):197-215.

[9]Gober P,Wentz E A,Lant T,et al.WaterSim:a simulation model for urban water planning in Phoe nix,Arizona,USA[J].Environment and Planning B: Planning and Design,2011,38(2):197-215.

[10]Viala E. Water for food, water for life a comprehensive assessment of water management in agr iculture[J]. Irrigation and Drainage Systems, 2008, 22(1): 127-129. 